\title{
A novel susceptibility locus at 2p24 for generalised epilepsy with febrile seizures plus
}

\author{
D Audenaert, L Claes, K G Claeys, L Deprez, T Van Dyck, D Goossens, J Del-Favero, \\ Paesschen, C Van Broeckhoven, P De Jonghe
}

Generalised epilepsy with febrile seizures plus (GEFS+) is a clinically and genetically heterogeneous epilepsy syndrome. Using positional cloning strategies, mutations in $S C N 1 B$, $S C N I A$, and GABRG2 have been identified as genetic causes of GEFS+. In the present study, we describe a large four generation family with GEFS+ in which we performed a $10 \mathrm{cM}$ density genome-wide scan. We obtained conclusive evidence for a novel GEFS+ locus on chromosome 2 p24 with a maximum two point logarithm of the odds (LOD) score of 4.22 for marker D2S305 at zero recombination. Fine mapping and haplotype segregation analysis in this family delineated a candidate region of $3.24 \mathrm{cM}$, corresponding to a physical distance of $4.2 \mathrm{Mb}$. Linkage to $2 \mathrm{p} 24$ was confirmed $(p=0.007)$ in a collection of 50 nuclear and multiplex families with febrile seizures and epilepsy. Transmission disequilibrium testing and association studies provided further evidence $(p<0.05)$ that $2 p 24$ is a susceptibility locus for febrile seizures and epilepsy. Furthermore, we could reduce the candidate region to a $2.14 \mathrm{cM}$ interval, localised between D2S1360 and D2S2342, based upon an ancestral haplotype. Identification of the disease gene at this locus will contribute to a better understanding of the complex genetic aetiology of febrile seizures and epilepsy.

$\mathrm{F}$ brile seizures (MIM 121210) represent the most common childhood convulsion disorder affecting 2-5\% of children between the ages of 6 months and 5 years. Seizures are usually generalised tonic-clonic and of brief duration. They are by definition associated with fever and occur without evidence of intracranial infections or other definable causes. Typical febrile seizures remit spontaneously before the age of 5 . Twin and family studies have shown that febrile seizures have a heritable component of about $70 \% .^{12}$ Most studies support a polygenic or multifactorial mode of inheritance. ${ }^{1-3}$ However, in some rare families, segregation of the febrile seizure phenotype is compatible with a monogenic inheritance model. ${ }^{23}$

Although infantile febrile seizures are mostly benign, patients have an increased risk for epilepsy later in life. Generalised epilepsy with febrile seizures plus (GEFS+, MIM 604233) is a familial epilepsy syndrome that links febrile seizures with epilepsy. ${ }^{4}$ It encompasses a continuum of phenotypes with mild and severe forms of epilepsy. Most affected individuals present with typical febrile seizures or atypical febrile seizures, that is, febrile seizures that persist beyond 5 years of age. In addition, patients can have afebrile seizures including generalised tonic-clonic, absence, myoclonic, or atonic seizures. The most severe forms of epilepsy in the GEFS+ spectrum are myoclonic-astatic epilepsy and severe myoclonic epilepsy of infancy. GEFS+ has an autosomal dominant inheritance pattern with reduced penetrance.

To date, eight chromosomal loci have been reported for febrile seizures and GEFS+: FEB1 at 8q13-q21, FEB2 at 19p13.3, FEB3 at 2q23-q24, FEB4 at 5q14-q15, FEB5 at 6q22-q24, GEFS+1 at 19q13.1, GEFS+2 at 2q21-q33, and GEFS+3 at $5 q 31.1-q 33.1 .^{5-13}$ Mutations in the $\beta 1$ subunit (SCNIB) and the $\alpha$ l subunit (SCNIA) of the voltage gated sodium channel, and mutations in the $\gamma 2$ subunit of the $\mathrm{GABA}_{\mathrm{A}}$ receptor $(G A B R G 2)$, have been identified in GEFS+ families that are, respectively, linked to the GEFS+1, GEFS+2, and GEFS+3 loci. ${ }^{10}$ 12-14

In this report, we describe a large non-consanguineous family with febrile seizures and epilepsy (fig 1) that was compatible with GEFS+. The family comprised 11 patients in four successive generations and one affected spouse and was from Flanders, the Dutch speaking region of Belgium. All individuals were clinically assessed by means of a structured interview. For all patients, information was obtained about seizure type, duration, age at onset, frequency, and association with fever. The parents or the older siblings of the patients primarily provided clinical information, and all spouses were interviewed for familial occurrence of seizures to exclude possible bilineal inheritance. The detailed clinical characteristics of all patients are shown in table 1 .

In summary, of the 11 patients, eight had seizures associated with fever, but none developed epilepsy later in life. The febrile seizures were generalised tonic-clonic. Most seizures were brief, but in two individuals (III.4 and III.10) they lasted for more than $30 \mathrm{~min}$. The age at onset was very similar, ranging between 6 months and 2.5 years. The number of seizures varied between one and three except for individual II.5 who experienced 23 seizures associated with fever. Three patients had epileptic seizures without a history of febrile seizures. The epilepsy phenotype in those individuals was variable. Patient III.5 presented with generalised tonic seizures, while individual III.6 had only absences. For individual I.1, no detailed clinical data could be obtained.

Before initiating a genome-wide scan, we performed a simulation study using SLINK to estimate the power of this family. ${ }^{15}{ }^{16}$ Two point logarithm of the odds (LOD) scores were calculated with MLINK software (version 5.1) from the LINKAGE package. ${ }^{17}$ All individuals with one or more febrile or epileptic seizures were considered affected. We assumed an autosomal dominant inheritance pattern with reduced disease penetrance and a disease frequency of 0.0001 . We set the disease penetrance at $90 \%$ based upon calculations according to the method of Johnson et al. ${ }^{3}$ Since the frequency of febrile seizures in the population is $2-5 \%$, we incorporated a $3 \%$ phenocopy rate. The data were analysed

Abbreviations: GEFS+, generalised epilepsy with febrile seizures plus; LOD, logarithm of the odds; NPL, non-parametric linkage; TDT, transmission disequilibrium test 


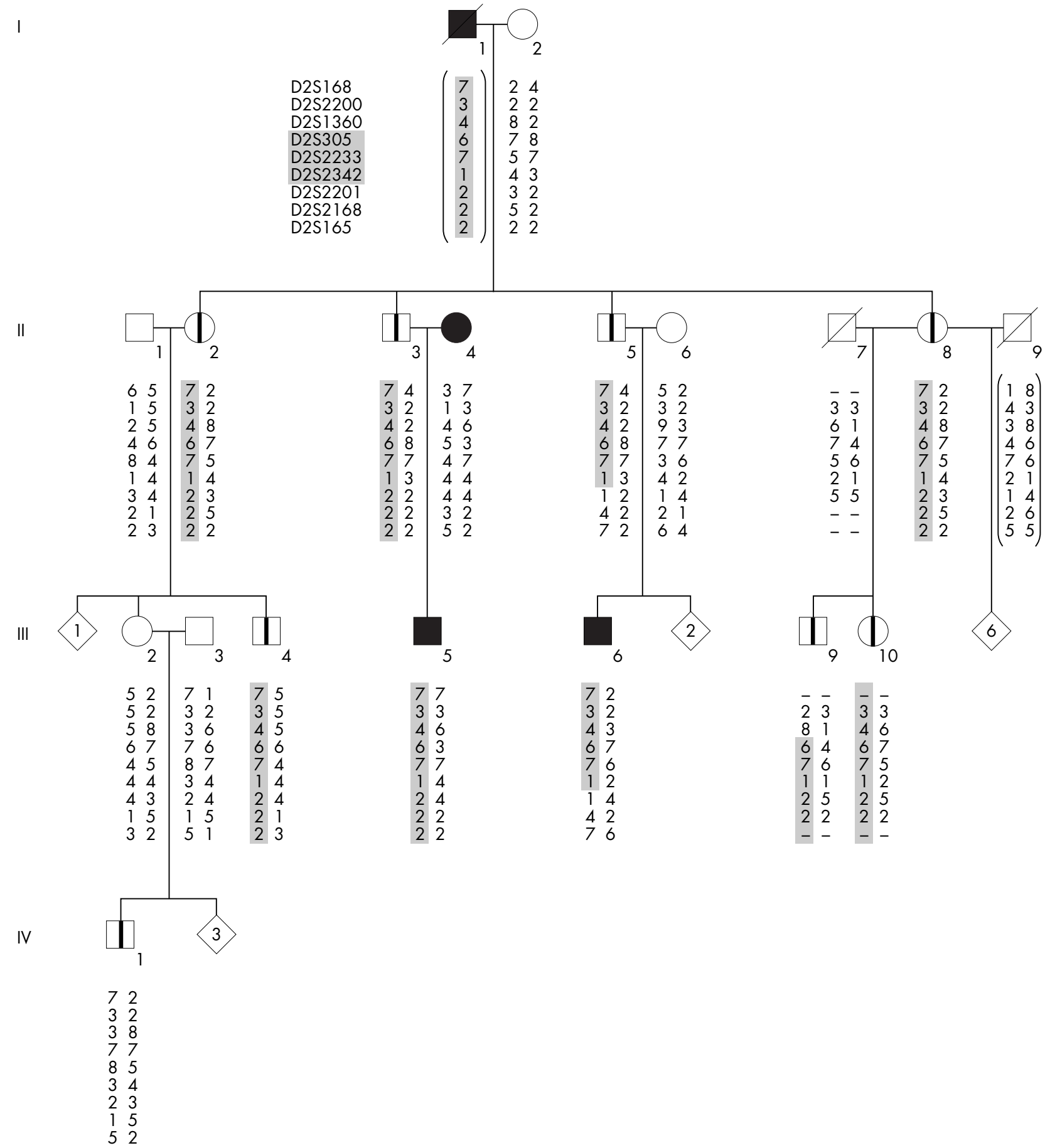

Figure 1 Pedigree of the four generation Belgian-Dutch family with GEFS+. Closed box: man with epileptic seizures; closed circle: woman with epileptic seizures; vertical bar in empty box: man with febrile seizures; vertical bar in empty circle: woman with febrile seizures; forward slash: deceased. Haplotypes of chromosome $2 p$ markers are shown under each symbol, a dash (-) indicates that genotypes were not obtained for the respective marker. To maintain confidentiality, the number of at risk individuals that were genotyped in the linkage analysis is indicated in a diamond. The disease haplotype is shaded. Haplotypes between brackets were inferred.

assuming equifrequent marker alleles and gender average recombination rates. A maximum two point LOD score of 5.07 was generated, using an eight allele marker with equal allele frequencies.

We obtained peripheral blood from all participating individuals and extracted genomic DNA using standard methods. All participants or their legal representative signed a written informed consent form, and the Medical Ethical Committee of the University of Antwerp approved this study.
We performed a $10 \mathrm{cM}$ genome-wide scan with the ABI Prism Linkage Mapping Set MD10 (Applied Biosystems, Foster City, CA) and genotyped 29 family members with 382 microsatellite markers distributed over the human genome. After amplification, PCR products were pooled and size fractionated on an ABI 3700 automated sequencer (Applied Biosystems). We used ABI Prism GeneScan and Genotyper version 3.7 software (Applied Biosystems) to determine allele sizes. For fine mapping, we analysed 16 additional 
Table 1 Clinical data of patients in the four generation GEFS+ family

\begin{tabular}{|c|c|c|c|c|c|c|c|c|}
\hline Patient & Gender & Age (years) & FS & ES & $\begin{array}{l}\text { Onset age } \\
\text { (months) }\end{array}$ & Seizure type & Duration (min) & No. of seizures \\
\hline 1.1 & $M$ & - & No & Yes & - & - & - & - \\
\hline II. 2 & $\mathrm{~F}$ & 63 & Yes & No & 17 & GTCS & 2 & 3 \\
\hline 11.3 & $M$ & 62 & Yes & No & 18 & GTCS & $3-5$ & 2 \\
\hline 11.5 & M & 55 & Yes & No & 18 & GTCS & 5 & 23 \\
\hline 11.8 & $\mathrm{~F}$ & 57 & Yes & No & $17-24$ & GTCS & - & 1 \\
\hline III. 4 & $M$ & 35 & Yes & No & 6 & GTCS & $2-30$ & 3 \\
\hline III. 5 & M & 37 & No & Yes & 9 years & GTS & $1-2$ & 3 \\
\hline III. 6 & $M$ & 24 & No & Yes & 9 & Absences & 5 & 1 \\
\hline 111.9 & $M$ & 16 & Yes & No & 30 & GTCS & 5 & 1 \\
\hline III. 10 & $\mathrm{~F}$ & 15 & Yes & No & 18 & GTCS & $>45$ & 1 \\
\hline IV.1 & $M$ & 14 & Yes & No & 15 & GTCS & $<1$ & 2 \\
\hline
\end{tabular}

ES, epileptic seizures; FS, febrile seizures; GTCS, generalised tonic-clonic seizures; GTS, generalised tonic seizures.

microsatellite markers selected from the Marshfield genetic map. Primer pairs for each marker were chosen with a proprietary algorithm implemented in the Multiplexer program (Goossens et al, unpublished data). For each marker, we calculated two point LOD scores and obtained a maximum LOD score of 4.22 for marker D2S305 at zero recombination (table 2 ), assuming the same genetic model as in the simulation study.

None of the previously reported loci showed evidence of linkage, and no other markers from the genome-wide panel gave a LOD score above 3 (data not shown). After analysis of recombination events in patients, we delineated a candidate region of $3.24 \mathrm{cM}$, localised between markers D2S1360 and D2S2201 (fig 1), corresponding to an estimated physical distance of $4.2 \mathrm{Mb}$. The telomeric boundary was defined by the recombinant haplotype in II.5 and his son III.6. A recombination in III.9 delimited the centromeric boundary. All patients except IV.l shared the haplotype segregating with the disease. His unaffected mother also did not inherit the disease haplotype, indicating that individual IV.l was likely a phenocopy and that his febrile seizures were unrelated to the genetic aetiology in the family. This is not unusual in GEFS+ families, and in part reflects the high frequency of febrile seizures $(2-5 \%)$ in the general population. It is also of interest that none of the unaffected at risk family members carried the disease haplotype, indicating that the GEFS+ phenotype is fully penetrant in this pedigree. This is rather exceptional as GEFS+ or febrile seizures usually show a disease penetrance varying between $60 \%$ and $90 \%$.

After establishing linkage at chromosome 2p24, an additional group of 50 families with febrile seizures and/or epilepsy (table 3) was analysed. All families were of Belgian-Dutch origin. The group comprised a total of 291 individuals of whom 142 were patients. The proband of each family presented with seizures that were associated with fever. For each proband, at least one of the parents was available and provided clinical
Table 3 Characteristics of the febrile seizures and/or the epilepsy families

\begin{tabular}{|c|c|c|c|}
\hline & $\begin{array}{l}2 \text { generation } \\
\text { (1 affected } \\
\text { offspring) }\end{array}$ & $\begin{array}{l}2 \text { generation } \\
\text { (>1 affected } \\
\text { offspring) }\end{array}$ & $\begin{array}{l}3 \text { or more } \\
\text { generation } \\
\text { ( } \geqslant 2 \text { patients) }\end{array}$ \\
\hline No. of families & 11 & 8 & 31 \\
\hline $\begin{array}{l}\text { No. of individuals } \\
\text { analysed }\end{array}$ & 31 & 36 & 224 \\
\hline $\begin{array}{l}\text { No. of patients } \\
\text { Phenotype of } \\
\text { patients }\end{array}$ & 21 & 20 & 101 \\
\hline FS & 17 & 15 & 87 \\
\hline $\mathrm{FS}+\mathrm{ES}$ & 4 & 1 & 6 \\
\hline ES & 0 & 5 & 8 \\
\hline
\end{tabular}

Table 4 Non-parametric linkage analysis

\begin{tabular}{llll}
\hline Marker & Distance $(\mathbf{c M})$ & NPL score & p value \\
\hline D2S1360 & 38.33 & 2.25 & 0.011 \\
D2S305 & 38.87 & 2.42 & 0.007 \\
D2S2233 & 39.93 & 2.43 & 0.007 \\
D2S2342 & 40.47 & 2.16 & 0.013 \\
D2S2201 & 41.57 & 1.79 & 0.032 \\
\hline
\end{tabular}

NPL, non-parametric linkage. Positions of the markers were obtained from the Marshfield genetic map.

information about seizure frequency and association with fever. Parents were interviewed to identify a possible positive history for febrile seizures in other family members. If other patients in the family were available, the patients and/or their parents were contacted and interviewed. Additional patients were considered affected if they had at least one unprovoked febrile and/or

Table 2 Two point LOD scores for markers at 2p24

\begin{tabular}{|c|c|c|c|c|c|c|c|c|}
\hline \multirow[b]{2}{*}{ Marker } & \multirow[b]{2}{*}{ Distance (cM) } & \multicolumn{7}{|c|}{ LOD scores at recombination fraction $\theta$ of } \\
\hline & & 0.00 & 0.01 & 0.05 & 0.10 & 0.20 & 0.30 & 0.40 \\
\hline D2S168* & 27.06 & 1.17 & 1.29 & 1.56 & 1.66 & 1.53 & 1.16 & 0.63 \\
\hline D2S2200 & 27.60 & 1.17 & 1.26 & 1.43 & 1.46 & 1.28 & 0.93 & 0.49 \\
\hline D2S1360 & 38.33 & 3.10 & 3.15 & 3.18 & 3.04 & 2.51 & 1.78 & 0.94 \\
\hline D2S305* & 38.87 & 4.22 & 4.15 & 3.87 & 3.51 & 2.73 & 1.87 & 0.96 \\
\hline D2S2233 & 39.93 & 3.03 & 2.99 & 2.79 & 2.52 & 1.90 & 1.23 & 0.55 \\
\hline D2S2342 & 40.47 & 3.57 & 3.51 & 3.25 & 2.92 & 2.23 & 1.52 & 0.77 \\
\hline D2S2201 & 41.57 & 1.65 & 2.56 & 2.98 & 2.94 & 2.49 & 1.81 & 0.98 \\
\hline D2S2168 & 45.30 & 1.04 & 1.95 & 2.36 & 2.32 & 1.92 & 1.33 & 0.67 \\
\hline D2S165* & 47.43 & -1.04 & -0.10 & 0.45 & 0.59 & 0.58 & 0.44 & 0.24 \\
\hline
\end{tabular}


Table 5 Allelic association analysis for five markers at 2 p24

\begin{tabular}{|c|c|c|c|c|c|c|c|}
\hline \multirow[b]{2}{*}{ Marker } & \multirow[b]{2}{*}{ Poverall } & \multirow[b]{2}{*}{ Alleles } & \multicolumn{2}{|c|}{ Proband } & \multicolumn{2}{|c|}{ Control } & \multirow[b]{2}{*}{$p$} \\
\hline & & & $n$ & $\%$ & $n$ & $\%$ & \\
\hline \multirow[t]{9}{*}{ D2S1360 } & 0.656 & 2 & 10 & 10 & 22 & 11.2 & 0.748 \\
\hline & & 3 & 6 & 6 & 16 & 8.2 & 0.502 \\
\hline & & 4 & 26 & 26 & 61 & 31.1 & 0.360 \\
\hline & & 5 & 10 & 10 & 19 & 9.7 & 0.933 \\
\hline & & 6 & 9 & 9 & 15 & 7.7 & 0.688 \\
\hline & & 7 & 10 & 10 & 19 & 9.7 & 0.933 \\
\hline & & 8 & 7 & 7 & 12 & 6.1 & 0.771 \\
\hline & & 9 & 6 & 6 & 13 & 6.6 & 0.834 \\
\hline & & Other & 16 & & 19 & & \\
\hline \multirow[t]{6}{*}{ D2S305 } & 0.262 & 2 & 10 & 10 & 23 & 11.7 & 0.654 \\
\hline & & 3 & 9 & 9 & 18 & 9.2 & 0.959 \\
\hline & & 4 & 12 & 12 & 35 & 17.9 & 0.192 \\
\hline & & 6 & 46 & 46 & 67 & 34.2 & $0.048^{*}$ \\
\hline & & 7 & 12 & 12 & 22 & 11.2 & 0.843 \\
\hline & & Other & 11 & & 31 & & \\
\hline \multirow[t]{8}{*}{ D2S2233 } & $0.048^{*}$ & 2 & 10 & 10 & 36 & 18.4 & 0.060 \\
\hline & & 4 & 13 & 13 & 43 & 21.9 & 0.063 \\
\hline & & 5 & 9 & 9 & 18 & 9.2 & 0.959 \\
\hline & & 6 & 13 & 13 & 26 & 13.3 & 0.949 \\
\hline & & 7 & 32 & 32 & 42 & 21.4 & $0.047^{*}$ \\
\hline & & 8 & 12 & 12 & 11 & 5.6 & 0.052 \\
\hline & & 9 & 7 & 7 & 14 & 7.1 & 0.964 \\
\hline & & Other & 4 & & 6 & & \\
\hline \multirow[t]{4}{*}{ D2S2342 } & 0.897 & 2 & 46 & 46 & 87 & 44.4 & 0.792 \\
\hline & & 5 & 15 & 15 & 33 & 16.8 & 0.685 \\
\hline & & 6 & 27 & 27 & 48 & 24.5 & 0.639 \\
\hline & & Other & 12 & & 28 & & \\
\hline \multirow{6}{*}{ D2S2201 } & 0.476 & 1 & 6 & 6 & 9 & 4.6 & 0.601 \\
\hline & & 5 & 8 & 8 & 17 & 8.7 & 0.844 \\
\hline & & 7 & 6 & 6 & 15 & 7.7 & 0.600 \\
\hline & & 8 & 64 & 64 & 112 & 57.1 & 0.256 \\
\hline & & 9 & 7 & 7 & 12 & 6.1 & 0.771 \\
\hline & & Other & 9 & & 31 & & \\
\hline
\end{tabular}

Only alleles with an observed frequency $>5 \%$ in the patients were included in the analysis. ${ }^{*} p<0.05$, statistically significant.

afebrile seizure. Mutations in SCNIA, SCNIB, and GABRG2 were excluded by mutation analysis of genomic DNA of each proband $^{18}$ (Audenaert et al, unpublished data).

To examine linkage to $2 \mathrm{p} 24$, we genotyped these families for three markers localised within the candidate region and two flanking markers, spanning a region of $3.24 \mathrm{cM}$. We calculated multipoint non-parametric linkage (NPL $\mathrm{Z}_{\text {all }}$ ) scores and associated $\mathrm{p}$ values, using the total stat command in the Genehunter program (http://linkage.rockefeller.edu/ soft/gh). Eleven families consisted of only one affected

Table 6 Two marker sliding window analysis

\begin{tabular}{|c|c|c|c|c|c|c|c|}
\hline \multirow[b]{2}{*}{ Haplotype markers } & \multirow[b]{2}{*}{ Poverall } & \multirow[b]{2}{*}{ Alleles } & \multicolumn{2}{|c|}{ Proband } & \multicolumn{2}{|c|}{ Control } & \multirow[b]{2}{*}{$p$} \\
\hline & & & $n$ & $\%$ & $n$ & $\%$ & \\
\hline \multirow[t]{4}{*}{ D2S1360-D2S305 } & 0.681 & $\mathrm{H}-2-6$ & 5 & 5 & 7 & 3.8 & 0.556 \\
\hline & & $\mathrm{H}-4-6$ & 11 & 11 & 17 & 9.2 & 0.517 \\
\hline & & $\mathrm{H}-4-7$ & 5 & 5 & 7 & 3.8 & 0.556 \\
\hline & & Other & 79 & & 165 & & \\
\hline \multirow[t]{5}{*}{ D2S305-D2S2233 } & $0.008^{*}$ & $\mathrm{H}-4-7$ & 4 & 4 & 7 & 3.8 & 0.854 \\
\hline & & $\mathrm{H}-6-6$ & 5 & 5 & 10 & 5.4 & 0.970 \\
\hline & & $\mathrm{H}-6-7$ & 17 & 17 & 12 & 6.5 & $0.003^{*}$ \\
\hline & & $\mathrm{H}-6-8$ & 4 & 4 & 2 & 1.1 & 0.085 \\
\hline & & Other & 70 & & 165 & & \\
\hline \multirow[t]{8}{*}{ D2S2233-D2S2342 } & 0.114 & $\mathrm{H}-4-2$ & 5 & 5 & 12 & 6.5 & 0.695 \\
\hline & & $\mathrm{H}-6-2$ & 9 & 9 & 13 & 7.1 & 0.463 \\
\hline & & $\mathrm{H}-7-2$ & 15 & 15 & 18 & 9.8 & 0.133 \\
\hline & & H-7-5 & 4 & 4 & 3 & 1.6 & 0.186 \\
\hline & & $\mathrm{H}-7-6$ & 8 & 8 & 11 & 6.0 & 0.428 \\
\hline & & $\mathrm{H}-8-6$ & 4 & 4 & 3 & 1.6 & 0.186 \\
\hline & & $\mathrm{H}-9-2$ & 4 & 4 & 6 & 3.3 & 0.672 \\
\hline & & Other & 51 & & 130 & & \\
\hline \multirow[t]{5}{*}{ D2S2342-D2S2201 } & 0.775 & $\mathrm{H}-2-8$ & 25 & 25 & 42 & 22.8 & 0.487 \\
\hline & & $\mathrm{H}-2-9$ & 5 & 5 & 2 & 1.1 & $0.033^{*}$ \\
\hline & & $\mathrm{H}-5-8$ & 7 & 7 & 18 & 9.8 & 0.523 \\
\hline & & $\mathrm{H}-6-8$ & 16 & 16 & 27 & 14.7 & 0.608 \\
\hline & & Other & 47 & & 107 & & \\
\hline
\end{tabular}

Only haplotype alleles with an observed frequency $>4 \%$ in the patients were included in the analysis.

${ }^{*} p<0.05$, statistically significant. 
offspring and were omitted from the NPL analysis. A maximum multipoint NPL $Z_{\text {all }}$ score of $2.43(p=0.007)$ was obtained at D2S2233 (table 4). The information content of the markers was higher than $80 \%$ throughout the $3.24 \mathrm{cM}$ region. These results indicated that the locus at $2 \mathrm{p} 24$ is involved in the genetic aetiology underlying the susceptibility for febrile seizures and epilepsy in these families.

To confirm this finding, we performed for each of the five markers at $2 \mathrm{p} 24$ a transmission disequilibrium test (TDT) with the probands of the 50 families, using the Genehunter tdt command. This showed that allele 6 at D2S305 was transmitted significantly more to the patients compared to other alleles at D25305 ( $p=0.022$; allele 6 was transmitted 29 times and not transmitted 14 times).

As a next step, we performed an association study and compared the allelic distribution between probands of the 50 families and 98 Belgian-Dutch population control individuals. Overall $\mathrm{p}$ values were calculated using CLUMP (http:// linkage.rockefeller.edu/soft/clump.html). The overall allelic distribution of the markers was not significantly different between patients and controls, except for D2S2233 (table 5; $\left.p_{\text {overall }}=0.048\right)$. Using the $\chi^{2}$ statistic, we compared allele frequencies between patients and controls. We found significant allelic association with febrile seizures at D2S305 and D2S2233 (table 5): allele 6 at D2S305 ( pallele6 $=0.048$; OR $1.64 ; 95 \%$ CI $1.00-2.68)$ and allele 7 at D2S2233 ( $\mathrm{p}_{\text {allele } 7}=$ 0.047; OR 1.73; 95\% CI 1.00-2.96).

These findings were further supported using sliding window analysis of two marker haplotypes. To obtain observed haplotypes, we genotyped the 50 probands with their parents and 49 triads of Belgian-Dutch population control individuals. Genehunter generated the most likely haplotypes of patients and control individuals. Using CLUMP, we compared the overall allelic distribution of the two marker haplotypes and found a highly significant overall $\mathrm{p}$ value at D2S305-D2S2233 (table 6; $p_{\text {overall }}=0.008$ ). We calculated the contribution of each haplotype to the overall $\mathrm{p}$ value using the $\chi^{2}$ statistic, and found that H-6-7 at D2S305D2S2233 was significantly overrepresented in patients (table 6; $\mathrm{p}_{\mathrm{H}-6-7}=0.003 ;$ OR 2.94; 95\% CI 1.34-6.43). These results demonstrated that a common haplotype at chromosome $2 \mathrm{p} 24, \mathrm{H}-6-7$, contributed to developing febrile seizures in the Belgian-Dutch population. Furthermore, the disease haplotype in the large linkage family also contained the H-67 allele at D2S305-D2S2233 (fig 1). This allowed us to further refine the candidate region at 2 p24 to a $2.14 \mathrm{cM}$ interval localised between D2S1360 and D2S2342, based upon ancestral recombination events. A p value less than 0.05 was also obtained for H-2-9 at D2S2342-D2S2201. However, the frequency of this haplotype allele in the control group (table $6 ; 1.1 \%$ ) was too low to provide conclusive evidence.

The chromosome 2p24 locus for febrile seizures contains 14 known and six putative genes. So far, the three genes involved in GEFS+, that is, SCNIB, SCN1A, and GABRG2, encode subunits of voltage gated or ligand gated ion channels. Therefore, one of the most attractive candidate genes in this locus is KCNS3 (voltage gated potassium channel, subfamily $S$, member 3 ). It encodes a subunit of the voltage gated potassium channel of the delayed rectifier type and is abundantly expressed in the brain. ${ }^{19}$ Further characterisation of KCNS3 and other genes at the chromosome 2p24 locus might lead to identification of the actual susceptibility alleles in the Belgian-Dutch population and the causal variant in our linkage family.

\section{ACKNOWLEDGEMENTS}

We are grateful to the patients and their relatives for their cooperation and participation in this study. We thank Iris Smouts for collecting blood samples and the people at the VIB Genetic Service Facility (http:// www.vibgeneticservicefacility.be) for the genetic analyses.

\section{ELECTRONIC-DATABASE INFORMATION}

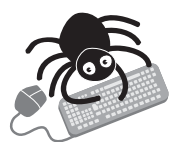

The following websites have been mentioned in this report: Center for Medical Genetics, Marshfield Medical Research Foundation, http://research. marshfieldclinic.org/genetics/; Laboratory of Statistical Genetics, Rockefeller University, http:// linkage.rockefeller.edu (for Genehunter and CLUMP) Online Mendelian Inheritance in Man (OMIM), http:// www.ncbi.nlm.nih.gov/Omim/ (for febrile seizures, and generalised epilepsy with febrile seizures plus); VIB Genetic Service Facility, http://www.vibgenetic servicefacility.be.

\section{Authors' affiliations}

D Audenaert, L Claes, K G Claeys, L Deprez, T Van Dyck, D Goossens, J Del-Favero, C Van Broeckhoven, P De Jonghe, Department of Molecular Genetics, Flanders Interuniversity Institute for Biotechnology, University of Antwerp, Antwerp, Belgium

K G Claeys, P De Jonghe, Division of Neurology, University Hospital of Antwerp, Antwerp, Belgium

W Van Paesschen, Division of Neurology, University Hospital of Leuven, Leuven, Belgium

Financial support was received from the Fund for Scientific Research Flanders (FWO-F), the Queen Elisabeth Medical Foundation, and the Interuniversity Attraction Poles (IUAP) program P5/19 of the Federal Science Policy Office, Belgium. DA is a PhD fellow of the FWO-F and LD of the Institute for Science and Technology (IWT), Belgium

Competing interests: none declared

All participants or their legal representative signed a written informed consent form, and the Medical Ethical Committee of the University of Antwerp approved this study

Correspondence to: Professor Peter De Jonghe, Department of Molecular Genetics (VIB8), Neurogenetics Research Group, University of Antwerp (UA), Universiteitsplein 1, 2610 Antwerp, Belgium; peter. dejonghe@ua.ac.be

Revised version received 22 March 2005

Accepted for publication 28 March 2005

Published Online First 12 April 2005

\section{REFERENCES}

1 Tsuboi T. Genetic analysis of febrile convulsions: twin and family studies. Hum Genet 1987;75:7-14.

2 Rich SS, Annegers JF, Hauser WA, Anderson VE. Complex segregation analysis of febrile convulsions. Am J Hum Genet 1987;41:249-57.

3 Johnson WG, Kugler SL, Stenroos ES, Meulener MC, Rangwalla I, Johnson TW, Mandelbaum DE. Pedigree analysis in families with febrile seizures. Am J Med Genet 1996;61:345-52.

4 Scheffer IE, Berkovic SF. Generalized epilepsy with febrile seizures plus. A genetic disorder with heterogeneous clinical phenotypes. Brain 1997; 120:479-90.

5 Wallace RH, Berkovic SF, Howell RA, Sutherland GR, Mulley JC. Suggestion of a major gene for familial febrile convulsions mapping to 8q13-21. J Med Genet 1996;33:308-12.

6 Johnson EW, Dubovsky J, Rich SS, O'Donovan CA, Orr HT, Anderson VE, Gil-Nagel A, Ahmann P, Dokken CG, Schneider DT, Weber JL. Evidence for a novel gene for familial febrile convulsions, FEB2, linked to chromosome 19p in an extended family from the Midwest. Hum Mol Genet 1998;7:63-7

7 Peiffer A, Thompson J, Charlier C, Otterud B, Varvil T, Pappas C, Barnitz C, Gruenthal K, Kuhn R, Leppert M. A locus for febrile seizures (FEB3) maps to chromosome 2q23-24. Ann Neurol 1999;46:671-8.

8 Nakayama J, Hamano K, Iwasaki N, Nakahara S, Horigome Y, Saitoh H, Aoki T, Maki T, Kikuchi M, Migita T, Ohto T, Yokouchi Y, Tanaka R, Hasegawa M, Matsui A, Hamaguchi H, Arinami T. Significant evidence for linkage of febrile seizures to chromosome 5q14-q15. Hum Mol Genet 2000;9:87-91.

9 Nabbout R, Prud'homme JF, Herman A, Feingold J, Brice A, Dulac O, LeGuern E. A locus for simple pure febrile seizures maps to chromosome 6q22-q24. Brain 2002;125:2668-80.

10 Wallace RH, Wang DW, Singh R, Scheffer IE, George AL Jr, Phillips HA Saar K, Reis A, Johnson EW, Sutherland GR, Berkovic SF, Mulley JC. Febrile seizures and generalized epilepsy associated with a mutation in the Na+-channel betal subunit gene SCN1B. Nat Genet 1998; 19:366-70 
11 Baulac S, Gourfinkel-An I, Picard F, Rosenberg-Bourgin M, Prud'homme JF, Baulac M, Brice A, LeGuern E. A second locus for familial generalized epilepsy with febrile seizures plus maps to chromosome 2q21-q33. Am J Hum Genet 1999;65:1078-85

12 Baulac S, Huberfeld G, Gourfinkel-An I, Mitropoulou G, Beranger A Prud'homme JF, Baulac M, Brice A, Bruzzone R, LeGuern E. First genetic evidence of GABA(A) receptor dysfunction in epilepsy: a mutation in the gamma2-subunit gene. Nat Genet 2001;28:46-8.

13 Wallace RH, Marini C, Petrou S, Harkin LA, Bowser DN, Panchal RG, Williams DA, Sutherland GR, Mulley JC, Scheffer IE, Berkovic SF. Mutant GABA(A) receptor gamma2-subunit in childhood absence epilepsy and febrile seizures. Nat Genet 2001;28:49-52.

14 Escayg A, MacDonald BT, Meisler MH, Baulac S, Huberfeld G, AnGourfinkel I, Brice A, LeGuern E, Moulard B, Chaigne D, Buresi C,
Malafosse A. Mutations of SCN1A, encoding a neuronal sodium channel, in two families with GEFS+2. Nat Genet 2000;24:343-5.

15 Ott J. Computer-simulation methods in human linkage analysis. Proc Nat Acad Sci U S A 1989;86:4175-8.

16 Weeks DE, OH J, Lathrop GM. SLINK: a general simulation program for linkage analysis. Am J Hum Genet 1990;47:A204.

17 Cottingham RW Jr, Idury RM, Schaffer AA. Faster sequential genetic linkage computations. Am J Hum Genet 1993;53:252-63.

18 Audenaert D, Claes L, Ceulemans B, Löfgren A, Van Broeckhoven C, De Jonghe $\mathrm{P}$. A deletion in $\mathrm{SCN} 1 \mathrm{~B}$ is associated with febrile seizures and earlyonset absence epilepsy. Neurology 2003;61:854-6.

19 Stocker M, Kerschensteiner D. Cloning and tissue distribution of two new potassium channel alpha-subunits from rat brain. Biochem Biophys Res Commun 1998;248:927-34.

\section{CORRECTION}

doi: 10.1136/jmg.2005.27433corr l

In the Letter to JMG titled, a genome screen of families at high risk for Hodgkin lymphoma: evidence for a susceptibility gene on chromosome 4 ( $\mathrm{J}$ Med Genet 2005;42 595-601) figure 1 was incorrect. The curves are missing from Chromosomes 16 and 19 A full corrected figure 1 is available on the JMG website at http://www.jmedgenet.com/ supplemental. 